\title{
The effects of thumb sucking habit on the development of malocclusions in preschool age children in Hilla city
}

Saba Mohamed Al-kinane, B.D.S. (1)

Zainab A.A.Al-Dahan, B.D.S, M.S.C. (2)

\begin{abstract}
Background: habit is any purposeless action repeated unconsciously. It is a sign of lack of harmony between the subject and the surrounding environment. Deleterious oral habits such as finger sucking could be one of the etiological factors for altered oro-facial growth development. This study conducted to explore the association between finger sucking habit and malocclusion in deciduous dentition.

Materials and method: Totally 40 chronic thumb sucker and 40 controls matching in age and gender were enrolled in the study. A study conducted by verifying different occlusal trait through the intra-oral examination. Thumb sucking habit diagnosed using data gathered from parents.

Results: The statistical analysis showed a highly significant difference $(p>0.01)$ in the occurrence of anterior open bite, increased over jet between study and controls, in addition to that thumb sucking habit increased the likelihood of development of anterior open bite, increased overjet and posterior cross bite by 39 folds, 40 folds and 3 folds respectively.

Conclusions: Thumb sucking habit found to be a risk factor for the development of anterior open bite and increased overjet.

Key words: Thumb sucking habit, anterior open bite, increased over jet, posterior cross bite. (Received: 15/8/2016; Accepted: 12/12/2016)
\end{abstract}

\section{INTRODUCTION}

Habit is a behavior that had been obtained through persistent repetition or physiologic exposure $^{(1)}$.

Repetitive behaviors are prevalent during infantile period and most of these behaviors begins and discontinue spontaneously ${ }^{(2)}$.

Oral habits are so common and one of the deleterious habits that represent a problem for both pediatricians and pedodontists ${ }^{(3,4)}$ because they had been implicated as an important environmental etiological factor associated with a faulty dento-facial development ${ }^{(5,6)}$.

Thumb/finger sucking habit are regarded to be the most prevalent of oral habit with detected incidence ranging from $13 \%$ to $100 \%$ at some time during infancy ${ }^{(3)}$.

Thumb sucking habit have been submitted to participate in the development of incorrect occlusion in the deciduous dentition and this faulty occlusion can be carried forward to the permanent occlusion as there is a common believe that the deciduous dental arches are the basis for normal development of permanent dental arches ${ }^{(7)}$.

Anterior open bite, increased overjet and posterior cross bite were the most recorded

(1) M.Sc. student, Department of Pedodontic and Preventive Dentistry, Collage of Dentistry, University of Baghdad.

(2) Professor, Department of Pedodontic and Preventive Dentistry, Collage of Dentistry, University of Baghdad occlusal traits associated with the thumb sucking (8-11).

The tendency toward developing of abnormal swallowing had been reported to increase in children with finger sucking, who showed a high frequency of compensatory tongue thrust leading to higher frequency of anterior open bite, unilateral or bilateral disto-occlusion and increased maxillary overjet ${ }^{(12)}$.

The severity of malocclusion developed as a consequence to thumb sucking habit depends on many factors including duration and times of doing the habit, the position of the finger in the mouth, the relation between the maxilla and mandible and the child's health ${ }^{(3,13)}$.

Larreson and Bishara ${ }^{(14)}$ stated that the malocclusions that had been attributed to thumb sucking habit were more harmful than those produced by other non-nutritive sucking habit such as pacifier sucking as the thumb used in the sucking habit will act as a lever producing a

force displacing maxillary teeth anteriorly causing greater increase in the overjet, elongation and proclination of anterior maxillary base than those caused by the pacifier.

In the first 3-4 years of age the deformity caused by thumb sucking is mainly confined to the anterior segment. This deformity usually temporary if the habit quitted before school age but if continues beyond this age children will invariably develop malocclusion at 12 years ${ }^{(15)}$. There is apparent positive relationship between oral habit and anterior open bite with a higher 
predisposition toward class II molar relationship in those with initial class $\mathrm{I}^{(16)}$.

Anterior open bite in turn had a bad outcomes such as the aesthetic problems, lingual interpositioning during swallowing, difficult biting on the incisors added to that speech problems represented by atypical phonation affect the production of the following phonetic sounds:/t/, $/ \mathrm{d} /, / \mathrm{n} /, / \mathrm{l} /, / \mathrm{r} /{ }^{(17)}$.

Pădure, Ngru ${ }^{(18)}$ stated that thumb sucking habit in addition to hereditary factor are important etiological factor for class II/ 1 malocclusion development.

Several authors stated that increased overjet attributed to thumb sucking habit resulted from elongation and advancement of anterior segment of maxillary arch in addition to the proclination of the upper incisors ${ }^{(8,9,19)}$.

Posterior cross bite may be results from thumb sucking habit practice if the habit continues after the age of 36 months. ${ }^{(11)}$ and it is persistent and not a self-corrected if the habit ceases (8) therefore, some malocclusion can be seen even in mixed dentition stage of dental development ${ }^{(20)}$. Al-Dawoody ${ }^{(9)}$ stated that posterior cross bite in thumb sucker developed as a result of decrease in maxillary arch width and increase in the mandibular arch width. The widening of mandibular arch resulted from positioning of tongue as it displaced by the thumb.

A previously conducted studies mentioned that posterior cross bite attributed to dummy sucking habit rather than thumb sucking habit $(8,11,20-22)$. The harmful effect of thumb sucking habit on development of occlusion was found to be the main reason behind mothers attempts to stop this habit in their children ${ }^{(23)}$.

\section{MATERIALS AND METODS}

A case control study conducted on 80 preschool children attending kindergarten and nursery schools in Hilla city. The first group of fourty children practicing the finger sucking habit at the time of examination and the other 40 children chosen to be a control for the cases and matching them in both age and gender.

The children with the thumb sucking habit diagnosed as a thumb sucker by using data obtained from parents through a selfadministered questionnaire.

Examination had been done during the school day in the day light and by using disposable dental mirror, millimeter graded vernier, face mask, and gloves. The results recorded in an organized case examination sheets.

Children with any oral or systemic condition that may influence the results; children with oral habits other than thumb sucking and children lost antagonist central incisors to whom overjet and over bite cant obtained were excluded from the study.

The occlusal relationship were examined by direct visual inspection of the teeth at centric occlusion and the arch characteristics were recorded using published definitions ${ }^{(7)}$.

\section{Overbite:}

Gained by measuring the vertical distance between the incisal edges of upper and lower incisors while teeth in centric relationship by instructing the child to open and close the mouth many times and to swallow the saliva before examination and sometimes it is necessary to gently guided the mandible into centric occlusion by the examiner. The distance had been regarded normal when upper incisors covered the lowers up to $3 \mathrm{~mm}$; and deep bite if it is greater than 3 $\mathrm{mm}$. while the open bite recorded present if there was no overlap between the upper and lower teeth with a minimum space of $1 \mathrm{~mm}$ between edges. Reverse over bite represent the coverage of upper incisors by lower incisors where they were in inverted position.

\section{Over jet:}

Gained by measuring the horizontal distance between the upper and lower incisors while teeth in centric relationship. The distance between the incisal of most prominent upper incisor and the buccal surface of corresponding lower incisor considered normal when it is about $3 \mathrm{~mm}$, while the distance more than $3 \mathrm{~mm}$ regarded as increased overjet. Reverse overjet( anterior cross bite) recorded when the incisors were in an inverted position with the lower incisal edge occluding buccaly to the upper incisal edge.

\section{Posterior cross bite:}

When the buccal cusps of mandibular molars where buccaly displaced regarding the buccal cusps of the upper molar, posterior cross bite recorded as present regardless of the side.

Data of this study had been translated into a computerized database structure. IBMSPSS version 21 computer software (IBM Statistical Package for Social Sciences) in association with Microsoft Excel were used for the statistical analysis.

\section{RESULTS}

Three occlusal trait which are anterior open bite, increased overjet and posterior cross bite were most commonly detected among children whom 
chronically suck their fingers with the anterior open bite recorded the highest frequency $(50 \%)$ followed by increased overjet and posterior cross bite respectively Fig.(1).

Results in table (1) showed that there is a highly significant differences between the cases and controls groups in the occurrence of both anterior open bite and increased overjet which were higher among cases group subject, while the difference between the two groups in the prevalence of posterior cross bite failed to reach the level of statistical significance.

The result of adjusted odds ratio indicated that thumb sucking habit is a risk factor for development of anterior open bite, increased overjet and posterior cross bite and increase the likelihood of their occurrence by 39 folds, 40 folds and 3 folds respectively.

There is an obvious difference in the occurrence of posterior cross bite among gender groups with males children were higher than females. However, the difference between gender groups of children practicing the thumb sucking habit in the occurrence of malocclusion doesn't large enough to give a statistical significance. Table (2).

Table (3) summarizes the frequencies of increased over jet, anterior open bite and posterior cross bite in different age groups of children with a thumb sucking habit.

The occurrence of posterior cross bite obviously higher in older ages (4 years) than the younger age (3 years) but this difference together with differences in the incidence rates of the increased overjet and anterior open bite not statically significant.

Further details about the distribution of the mentioned malocclusions among age and gender group seen in tables (4),(5),(6).

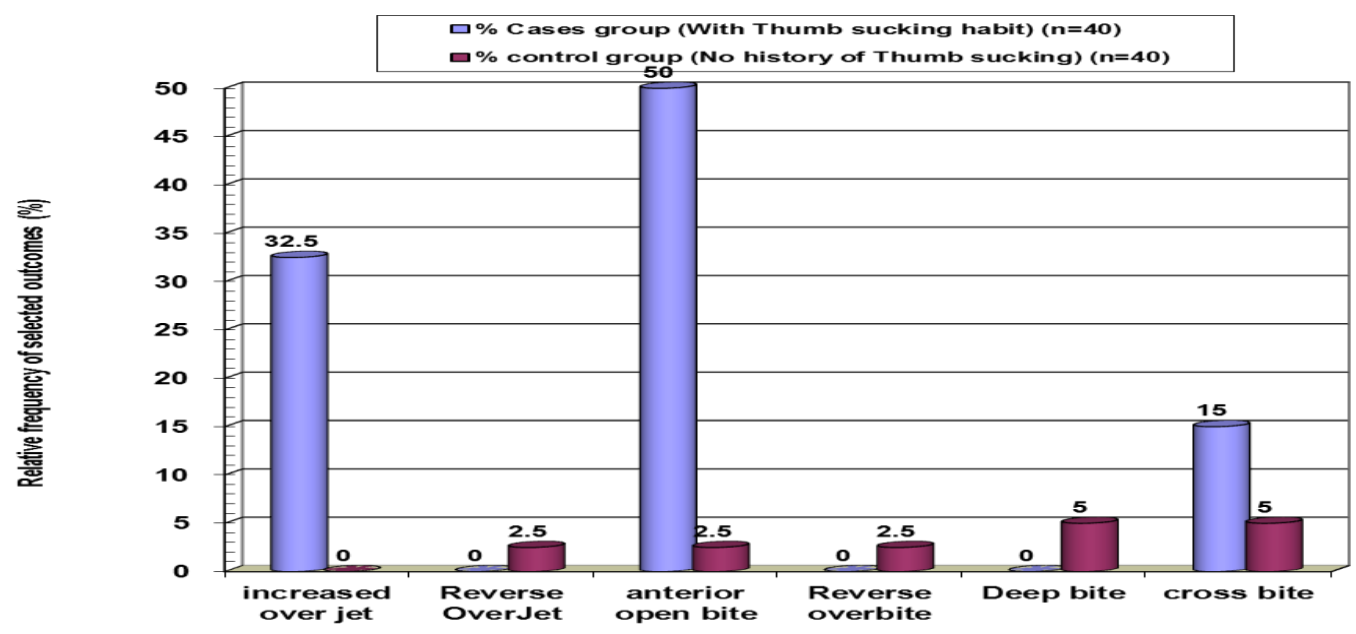

Figure 1: Bar chart showing the relative frequency of selected outcomes in subjects with a positive history of thumb sucking habit compared to controls.

Table 1: The risk of having selected outcomes in subjects with positive thumb sucking habit compared to controls.

\begin{tabular}{|c|c|c|c|c|c|c|c|c|}
\hline \multirow{3}{*}{ variables } & \multicolumn{4}{|c|}{ Thumb sucking } & \multirow{3}{*}{ OR } & \multirow{3}{*}{$\begin{array}{c}\text { Inverse } \\
\text { OR }\end{array}$} & \multirow{3}{*}{ 95\% CI OR } & \multirow{3}{*}{$\mathbf{P}$} \\
\hline & \multicolumn{2}{|c|}{ Negative } & \multicolumn{2}{|c|}{ positive } & & & & \\
\hline & $\mathbf{N}$ & $\%$ & $\mathbf{N}$ & $\%$ & & & & \\
\hline Increased over jet & 13 & 32.5 & $\mathbf{0}$ & $\mathbf{0}$ & 39.76 & $* *$ & $(4.9$ - 319.9) & $>0.001[S]$ \\
\hline Anterior open bite & 20 & 50 & 1 & 2.5 & 39 & $* *$ & $(4.9-312.2)$ & $>0.001[\mathrm{~S}]$ \\
\hline Posterior cross bite & 6 & 15 & 2 & 5 & 3.35 & $* *$ & $(0.63-17.74)$ & $1.103[\mathrm{NS}]$ \\
\hline Deep bite & $\mathbf{0}$ & $\mathbf{0}$ & 2 & 5 & 0.19 & 5.26 & $(0.02-1.91)$ & $0.24[\mathrm{NS}]$ \\
\hline Reverse over bite & $\mathbf{0}$ & $\mathbf{0}$ & 1 & 2.5 & $\mathbf{0 . 3 3}$ & 3.08 & $(0.03-3.73)$ & $0.500[\mathrm{NS}]$ \\
\hline Reverse overjet & $\mathbf{0}$ & $\mathbf{0}$ & 1 & 2.5 & 0.33 & 3.08 & $(0.03-3.73)$ & $0.500[\mathrm{NS}]$ \\
\hline
\end{tabular}


Table 2: The relative frequency of selected outcomes by gender among cases group only.

\begin{tabular}{|l|c|c|c|c|c|}
\hline \multirow{2}{*}{ Malocclusions } & \multicolumn{4}{|c|}{ Gender } & \multirow{2}{*}{ P } \\
\cline { 2 - 5 } & \multicolumn{2}{|c|}{ Females $(\mathrm{n}=22)$} & \multicolumn{2}{|c|}{ Males $(\mathbf{n = 1 8})$} & \\
\cline { 2 - 5 } & $\mathbf{N}$ & $\%$ & $\mathrm{~N}$ & $\%$ & \\
\hline Increased over jet & $\mathbf{8}$ & $\mathbf{3 6 . 4}$ & $\mathbf{5}$ & $\mathbf{2 7 . 8}$ & $\mathbf{0 . 5 6}[\mathrm{NS}]$ \\
\hline Anterior open bite & $\mathbf{1 2}$ & $\mathbf{5 4 . 5}$ & $\mathbf{8}$ & $\mathbf{4 4 . 4}$ & $\mathbf{0 . 5 3}[\mathrm{NS}]$ \\
\hline Cross bite & $\mathbf{5}$ & $\mathbf{2 2 . 7}$ & $\mathbf{1}$ & $\mathbf{5 . 6}$ & $\mathbf{0 . 2}[\mathrm{NS}]$ \\
\hline
\end{tabular}

Table 3: The relative frequency of selected outcomes by age among cases group only.

\begin{tabular}{|c|c|c|c|c|c|}
\hline \multirow{3}{*}{ Malocclusions } & \multicolumn{4}{|c|}{ Age (years) } & \multirow[b]{3}{*}{$\mathbf{P}$} \\
\hline & \multicolumn{2}{|c|}{3 years old $(n=17)$} & \multicolumn{2}{|c|}{4 years old $(n=23)$} & \\
\hline & $\mathbf{N}$ & $\%$ & $\mathbf{N}$ & $\%$ & \\
\hline Increased over jet & 4 & 23.5 & 9 & 39.1 & $0.3[\mathrm{NS}]$ \\
\hline Anterior open bite & 10 & 58.8 & 10 & 43.5 & $0.34[\mathrm{NS}]$ \\
\hline Cross bite & 1 & 5.9 & 5 & 21.7 & $0.22[\mathrm{NS}]$ \\
\hline
\end{tabular}

Table 4: Distribution of anterior open bite malocclusion among cases and controls group.

\begin{tabular}{|c|c|c|c|c|c|c|c|}
\hline \multirow{3}{*}{\multicolumn{2}{|c|}{ Anterior open bite }} & \multirow[b]{3}{*}{ Total N } & \multicolumn{2}{|c|}{ Cases } & \multicolumn{3}{|c|}{ Controls } \\
\hline & & & \multicolumn{2}{|c|}{ Anterior open bite } & \multirow{2}{*}{$\begin{array}{c}\text { Total } \\
\mathbf{N}\end{array}$} & \multicolumn{2}{|c|}{ Anterior open bite } \\
\hline & & & $\mathbf{N}$ & $\%$ & & $\mathbf{N}$ & $\%$ \\
\hline \multirow{3}{*}{ 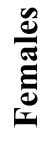 } & 3 years & 6 & 4 & 66.7 & 5 & $\mathbf{0}$ & $\mathbf{0 . 0}$ \\
\hline & 4 years & 61 & 8 & $\mathbf{5 0 . 0}$ & 16 & $\mathbf{0}$ & $\mathbf{0 . 0}$ \\
\hline & Total & 22 & 12 & 54.5 & 22 & $\mathbf{0}$ & $\mathbf{0 . 0}$ \\
\hline \multirow{3}{*}{$\frac{\tilde{\sigma}}{\tilde{\sigma}}$} & 3 years & 66 & 6 & 54.5 & 11 & $\mathbf{0}$ & $\mathbf{0 . 0}$ \\
\hline & 4 years & 7 & 2 & 28.6 & 7 & 1 & 14.3 \\
\hline & Total & 18 & 8 & 44.4 & 18 & 1 & 5.6 \\
\hline \multirow{3}{*}{ సี } & 3 years & 61 & 10 & 58.8 & 17 & $\mathbf{0}$ & $\mathbf{0 . 0}$ \\
\hline & 4 years & 23 & 10 & 43.5 & 23 & 1 & 4.3 \\
\hline & Total & 40 & 20 & 50.0 & 40 & 1 & 2.5 \\
\hline
\end{tabular}

Table 5: Distribution of increased over jet occlusal trait among cases and controls group.

\begin{tabular}{|c|c|c|c|c|c|c|c|}
\hline \multirow{3}{*}{\multicolumn{2}{|c|}{ Increased over jet }} & \multicolumn{3}{|c|}{ Non thumb sucking } & \multicolumn{3}{|c|}{ Thumb sucking } \\
\hline & & \multirow[t]{2}{*}{$\begin{array}{c}\text { Total } \\
\mathbf{N}\end{array}$} & \multicolumn{2}{|c|}{$\begin{array}{c}\text { Positive increased } \\
\text { overjet }\end{array}$} & \multirow[t]{2}{*}{$\begin{array}{c}\text { Total } \\
\mathbf{N}\end{array}$} & \multicolumn{2}{|c|}{$\begin{array}{c}\text { Positive increased } \\
\text { overjet }\end{array}$} \\
\hline & & & $\mathbf{N}$ & $\%$ & & $\mathbf{N}$ & $\%$ \\
\hline \multirow{3}{*}{ 产 } & 3 years & 6 & 3 & 50 & 6 & $\mathbf{0}$ & 0.0 \\
\hline & 4 years & 16 & 5 & 31.3 & 16 & $\mathbf{0}$ & 0.0 \\
\hline & Total & 22 & 8 & 36.4 & 22 & $\mathbf{0}$ & 0.0 \\
\hline \multirow{3}{*}{$\frac{\tilde{g}}{\pi}$} & 3 years & 11 & 1 & 9.1 & 11 & $\mathbf{0}$ & 0.0 \\
\hline & 4 years & 7 & 4 & 57.1 & 7 & $\mathbf{0}$ & 0.0 \\
\hline & total & 18 & 5 & 27.8 & 18 & $\mathbf{0}$ & 0.0 \\
\hline
\end{tabular}


Table 6: Distribution of posterior cross bite among cases and controls group.

\begin{tabular}{|c|c|c|c|c|c|c|c|}
\hline \multirow{3}{*}{\multicolumn{2}{|c|}{ Posterior cross bite }} & \multicolumn{3}{|c|}{ 'ases group } & \multicolumn{3}{|c|}{ 'ontrol group } \\
\hline & & \multirow[t]{2}{*}{$\begin{array}{c}\text { Total } \\
\mathbf{N}\end{array}$} & \multicolumn{2}{|c|}{$\begin{array}{c}\text { Posterior cross } \\
\text { bite }\end{array}$} & \multirow[t]{2}{*}{$\begin{array}{c}\text { Total } \\
\mathbf{N}\end{array}$} & \multicolumn{2}{|c|}{ Posterior cross bite } \\
\hline & & & $\mathbf{N}$ & $\%$ & & $\mathbf{N}$ & $\%$ \\
\hline \multirow{3}{*}{  } & 3 years & 6 & 1 & 16.7 & 6 & $\mathbf{0}$ & 00. \\
\hline & 4 years & 16 & 4 & 25 & 16 & $\mathbf{0}$ & 0.0 \\
\hline & Total & 22 & 5 & 22.7 & 22 & $\mathbf{0}$ & 0.0 \\
\hline \multirow{3}{*}{$\frac{0}{\tilde{\pi}}$} & 3 years & 11 & $\mathbf{0}$ & $\mathbf{0 . 0}$ & 11 & 2 & 18.2 \\
\hline & 4 years & 7 & 1 & 14.3 & 7 & $\mathbf{0}$ & $\mathbf{0 . 0}$ \\
\hline & total & 18 & 1 & 5.6 & 18 & 2 & 11.1 \\
\hline \multirow{3}{*}{$\stackrel{\pi}{\mathscr{T}}$} & 3 years & 17 & 1 & 5.9 & 17 & 2 & 11.8 \\
\hline & 4 years & 23 & 5 & 21.7 & 23 & $\mathbf{0}$ & 0.0 \\
\hline & Total & 40 & 6 & 15 & 40 & 2 & 5.0 \\
\hline
\end{tabular}

\section{DISCUSSION}

The occurrence of anterior open bite, increased over jet and posterior cross bite were higher among the children who were practicing the oral habit, thumb sucking, than control group this result in accordance with other studies $(16,24-28)$. The most striking differences between cases and controls group were the incidence of anterior open bite and the relative increase in overjet which were significantly more prevalent in cases group. Indeed none of thumb sucking group children show an increase in the overjet measurement this is in accordance with a previous study by Botham ${ }^{(29)}$.

The most dramatic evidence of the influence of thumb sucking habit on development of occlusion represented by the high occurrence of anterior open bite among thumb sucking practicing group this result in agreement with other researches ${ }^{(12}$, 30).

The adjusted odds ratio of anterior open bite indicates that thumb sucking habit was a risk factor for the development of anterior open bite by 39 folds.

This study found a highly significant statistical difference for the occurrence of increased overjet in thumb sucking children; this is in agreement with other researches ${ }^{(8,12)}$ who reported that thumb sucking causes more Class II division 1 types of malocclusion. In addition to that thumb sucking habit appeared to increase possibility of developing such malocclusion by 40 folds. This study concluded that there is no statistical difference between the cases group and controls group in the occurrence of posterior cross bite this result in accordance with Singh et al and Miotto et al ${ }^{(12,22)}$ but, disagree with results of previously conducted studies $(27,30)$ who found that the posterior cross bite had been observed to directly associated with oral habits

The adjusted odds ratio for posterior cross bite was giving an indication that thumb sucking habit was a risk factor and increasing 3 times the likelihood of the development of posterior cross bite.

From comparing the occurrence of malocclusions in cases group only the study showed that the frequencies of malocclusion are not age related neither gender related as there is no statistical difference among age and gender groups in the occurrence of malocclusions attributed to the oral habit this agree with Adair study ${ }^{(31)}$.

Occlusal traits including anterior open bite, increased over jet and posterior cross bite were more prominent among children practicing thumb sucking habit this may be attributed to the forceful sucking of the thumb with associated strong buccal and lip musculature contraction in addition to the position of the thumb between teeth this is in agreement with Kamdar and AlShahrani ${ }^{(32)}$.

\section{REFERENCES}

1. Merriam-Webster. "Habit definition and more from free Merriam-Webster dictionary", 2011.

2. Rajchanovska D, Zafirova-Ivanovska B.Oral habits among pre-elementary children in Bitola. Biol Med Sci 2012; 33(1):157-69.

3. Maguire JA. The evaluation and treatment of pediatric oral habits. Dental Clin North Am 2000;44(3):659-69.

4. Carlsson GE, Egermar k, Magnusson T. Predictors of bruxism, other oral parafunctions, and tooth wear over a 20-year follow-up period. $\mathrm{J}$ Orofac Pain 2003;17(1):50-7.

5. Warren JJ, Levy SM, Nowak AJ, Tank S. Nonnutritive sucking behaviors in preschool children: a longitudinal study. Pediatr Dent 2000; 22(3):187-91. 
6. Kharbanda O, Sidhhu S, Sundaram K, Shukla D. Oral habits in school going children of Delhi: A prevalence study. J Indian Soc Pedo Prev Dent 2003;21(3):120-4.

7. Moimaz, SAS. Garbin AJI, Lima AMC, Lolli, LF, Saliba, O. Garbin CAA. Longitudinal study of habits leading to malocclusion development in childhood. BMC Oral Health 2014; 14(96): 26.

8. Warren JJ, Bishara SE. Duration of nutritive and nonnutritive sucking behaviors and their effects on the dental arches in the primary dentition. Am J Orthod Dentofacial Orthop 2002;121(4):347-56.

9. Al-Dawoody A. Finger sucking prevalence. Contributing factors and effect on occlusion. AlRafidain Dent J 2004; 4(4): 135-42.

10. Ozawa N, Hamada S, Tekekoshi F, Shinji H. A study on non-nutritive sucking habits in young Japanese children. Pediatr Dent J 2005;15(1):64-71.

11. Duncan K, McNamara C, Ireland AJ, Sandy J. Sucking habits in childhood and the effects on the primary dentition: Findings of the Avon longitudinal study of pregnancy and childhood. Int J Paediatr Dent 2008;18(3):178-88.

12. Singh SP, Utreja A, Chawla HS. Distribution of malocclusion types among thumb suckers seeking orthodontic treatment. J Indian Soc Pedod Prevent Dent 2008;26(7): 114-7.

13. Yemitan TA, DaCosta OO, Sanu OO, Isiekwe MC. Effects of digit sucking on dental arch dimensions in the primary dentition. Afri J Medicine Med Sci. 2010;39(1):55-61.

14. Larreson E, Bishara S. Pacifier and digit sucking habits (EVIDENCE FOR PRACTICE). Canadian Journal Of Dental Hygiene 2007;42(1):22-9.

15. Franco VV, Gorritxo BG. Pacifier sucking habit and associated dental changes. Importance of early diagnosis. An Pediatr (Barc) 2011;77(6):374-80.

16. Warren JJ, Slayton RL, Bishara SE, Levy S, Yonezu T, Kanellis M. Effects of nonnutritive sucking habits on occlusal characteristics in the mixed dentition. Pediatr Dent 2005;27(6):445-450.

17. Ize-Iyamu IN, Isiekwe MC. Prevalence and factors associated with anterior open bite in 2 to 5 year old children in Benin City, Nigeria. Afri Health Sci 2012;12(4).

18. Pădure H, Ngru AR, Stanciu D. The Class II/1 anomaly of hereditary etiology vs. Thumb-sucking etiology. J Med Life 2012; 5(2):239-41.

19. Kato M, Watanabe K, Kato E, Hatto H, Daito M. Three dimentional measurement of the palate using the semiconductor laser: on the influence of the palate of maxillary protrusion with finger sucking. Pediatr Dent J 2009;19(1):25-9.

20. Montaldo L, Montaldo P, Cuccaro P, Caramico N, Minervini G. Effects of feeding on non-nutritive sucking habits and implications on occlusion in mixed dentition. Int J Paediatr Dent 2011; 21(1): 68-73.

21. Bishara SE, Warren JJ, Broffitt B, Levy SM. Changes in the prevalence of nonnutritive sucking patterns in the first 8 years of life. Am J Orthod Dentofacial Orthop 2006;130(1):31-6.

22. Miotto M, Cavalcante W, Godoy L, Campos D, Barcellos L. Prevalence of posterior cross bite in 3-5 years-old children from Vitoria, Brazil. Brazilian Research In Pediatric Dentistry And Integrated Clinic 2015;15(1):57-64.

23. Chopra A, Lakhanpal M, Singh V, Gupta N, Rao NC, Suri V. The habit of the digit sucking among children and the attitude of mother's toward the habit in India. TMU J Dent 2015;2(1):1-4.

24. Bishara S. Textbook of orthodontics. Philadelphia: WB Saunders, 2002.

25. Luz CLF, Garib DJ, Arouca R. Association between breast feeding duration and mandibular retrusion, a cross sectional study of children in mixed dentition. Am Orthod Dentofacial Orthop 2006;130(4):531-4.

26. Barbosa C, Vasquez S, Parada MA, Gonzalez JC, Jackson C, Yanez N, Gelaye B, Fitzpatrick AL. The relationship of bottle feeding and other sucking behaviors with speech disorder in Patagonian preschoolers. BMC Pediatrics. 2009;9(66):1-8.

27. Melnik S, Vagner MV, Hocevar-Boltezar I, Ovsenik M. Posterior cross bite in deciduous dentition period, its relation with sucking habits, irregular orofacial functions and otolaryngological findinga. Am $\mathrm{J}$ Orthod Dentofacial Orthop 2010;138(1):32-40.

28. Aznar T, Galán AF, Marín I, Domínguez A. Dental Arch Diameters and Relationships to Oral Habits. Angle Orthod 2006;76(3): 441-5.

29. Botham A. The effects of thumb sucking on dental charecterstics in primary dentition. Johannesburg: Witwatersrand, 2011.

30. Kasparaviciene K, Sidlauskas A, Zasciurinskiene E, Vasiliauskas A, Juodzbalys G, Sidlauskas M, Marmaite U. The prevalence of malocclusion and oral habits among 5-7 years old children. Med Sci Monit. 2014;20:2036-42.

31. Adair SM. Pacifier use in children: A review of recent literature. Pediatr Dent 2003; 25(5): 449-58.

32. Kamdar RJ, Al-Shahrani I. Damaging Oral Habits. J Int Oral Health 2015;7(4):85-7.

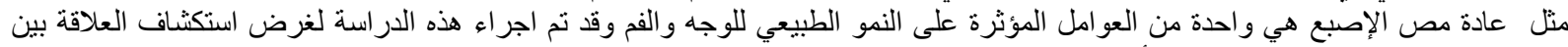

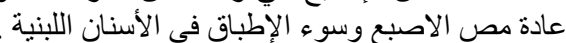

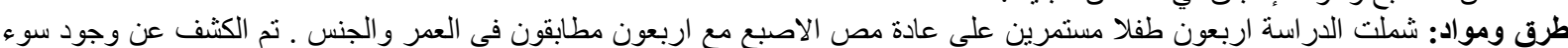

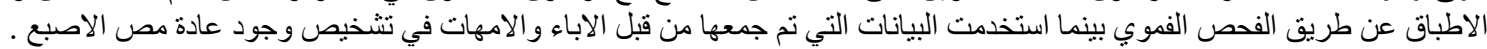

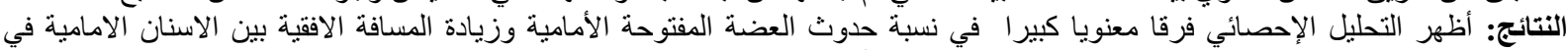

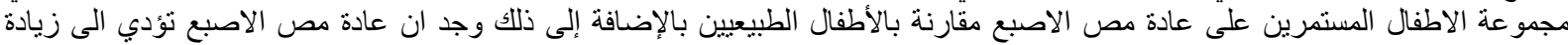

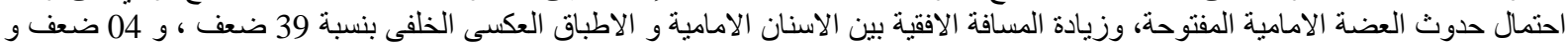

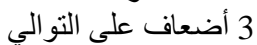
الاستنتاج: عادة مص الاصبع التبع عامل خطر لتطوير العضة الامامية المفتوحة وزيادة المسافة الافقية بين الاسنان الامامية.
} 
